\title{
La segregación, los guetos y la integración social urbana: mitos y claves
}

\author{
FRANCISCO SABATINI** e ISABEL BRAIN*** \\ ** Profesor Titular, Instituto de Estudios Urbanos y Territoriales, Pontificia Universidad Católica de Chile \\ *** Coordinadora ProUrbana, Pontificia Universidad Católica de Chile
}

\begin{abstract}
Naturalistic" views on the socio-spatial segregation of Latin American cities tend to dominate academic and public policy discussions. Social inequality or "classism", which is indeed strong and persistent traits of these societies, would make segregation inevitable and efforts to control it would be illusory. In contrast, the authors argue that there are no cultural, sociological or economic obstacles to reducing segregation. The authors highlight the importance of land policies focused on reducing segregation given the growth of ghettos characterized by desperation and crime in historically segregated poor neighborhoods.
\end{abstract}

KEYWORDS: residential segregation, ghettoes, social integration, Latin America, Chile

RESUMEN Predominan en el medio académico y político las nociones "naturalistas" sobre la segregación social del espacio en las ciudades latinoamericanas. Las desigualdades o el "clasismo", hechos fuertes y persistentes, harían de la segregación algo inevitable; y de las propuesta para controlarla, algo ilusorio. En contraposición, los autores del artículo argumentan que no existen impedimentos culturales, sociológicos ni económicos para reducir la segregación. Los autores destacan la importancia de contar con políticas de suelo orientadas por ese objetivo, considerando el avance de los guetos de desesperanza y crimen en los tradicionales barrios populares segregados.

PALABRAS CLAVES: Segregación residencial, guetos, integración social, América Latina, Chile 


\section{Introducción}

No existen impedimentos culturales, sociológicos ni económicos para conseguir menores grados de segregación social del espacio en las ciudades latinoamericanas, objetivo que debe ocupar un lugar crítico en la política pública considerando que los barrios populares segregados se están "guetizando" (drogas, crimen y deserción escolar, entre otros problemas).

Estas dos afirmaciones, combinadas, constituyen la tesis central de estas páginas. Nuestra atención estará centrada en las ciudades chilenas, aunque pretendemos que la tesis tiene validez para las ciudades de América Latina, cuyo contexto cultural, sociológico y económico es similar al de aquéllas. Nos proponemos argumentar en su favor, primero, confrontando algunos mitos corrientes sobre la segregación y, segundo, escudriñando ciertas claves específicas de su contra-cara, la integración social urbana.

\section{Mito Uno. Da lo mismo dónde vivan las personas pobres y vulnerables; lo que importa es que tengan casa}

¡Qué más da dónde vivan, cuando lo realmente crucial es que haya tanta pobreza y vulnerabilidad social, tantas familias sin casa, tanta desigualdad! Esta es una creencia popular entre gentes de izquierda. Lo verdaderamente importante es que las personas accedan a la vivienda, siendo la segregación un mal menor. Todavía más, la segregación podría no ser tan negativa en la medida que puede facilitar la organización política de estos grupos y fortalecer su capacidad de presión sobre el Estado.

En la mayoría de los países, desarrollados o no, la reforma económica ha vuelto más inestables y difíciles las condiciones de inserción laboral y política de los grupos urbanos de menores ingresos. Empleos de menor calidad y estabilidad, y la desaparición de las formas tradicionales de inserción de estos grupos y sus organizaciones en el juego político y los partidos, hacen del lugar donde viven en la ciudad una cuestión perentoria. Siempre ha sido importante la localización, pero ahora más.

La salida masiva de hogares pobres desde las áreas centrales de las ciudades de los Estados Unidos a partir de los años noventa (Jargowsky, 2003), especialmente hacia el primer anillo de suburbios, sería efecto de la búsqueda de una mejor "geografía de oportunidad" -la expresión es de Galster y Killen (1995). La expulsión de residentes (arrendatarios) en complejos de public housing debido a los procesos de gentrificación está, sin duda, contribuyendo a dicho éxodo, pero es materia pendiente de investigación saber cuántos están saliendo por su propia decisión en búsqueda de mejores oportunidades.

El crecimiento de los hogares bajo la línea de la pobreza en el primer anillo de suburbios, donde hay más oferta de espacios residenciales tugurizados, así lo sugiere. Los empleos se han "suburbanizado" en grado significativo en las ciudades de ese país en las últimas décadas, lo que hace explicable un desplazamiento de los grupos más pobres hacia la periferia urbana. 
Asimismo, entre los dos últimos censos de población crecieron demográficamente las favelas mejor localizadas de Rio de Janeiro, a pesar de ser las más densas de la ciudad y, por lo mismo, las con menos espacio disponible; y la población en villas miseria en la parte central de Buenos Aires, o Capital Federal, se duplicó entre 1991 y 2001, a pesar de que la población total del área disminuyó cerca de un 8 por ciento ${ }^{1}$. Hay ejemplos chilenos de este fenómeno, los que cubriremos más adelante.

\section{Mito Dos. A mayor desigualdad social, más segregación residencial en la ciudad}

Quizás sea ésta la idea más popular y, asimismo, la más inexacta sobre la segregación residencial. Se pregona y propaga no sólo en los países latinoamericanos sino que asimismo en otras latitudes. Es la forma más fácil y esquemática de entender las relaciones entre "lo social" y "lo espacial". Es recurrente entre arquitectos, geógrafos, urbanistas y otros profesionales que muestran predilección por representar los procesos sociales urbanos a través de planos, esquemas y diagramas. El espacio urbano hace de espejo sobre el que se reflejan las desigualdades sociales. De allí que podamos denominar esta noción como "tesis del espejo".

Pero la realidad se encarga de desmentirla una y otra vez. Nos referiremos más adelante al contraste entre las ciudades del Brasil y las de los Estados Unidos, las primeras más desiguales y las segundas más segregadas. También discutiremos los casos de las ciudades europeas preindustriales y las actuales de la India, donde también se combinan profundas desigualdades sociales con altos grados de mezcla social en el espacio.

¿Podrían las menores diferencias sociales estimular más segregación; y las mayores diferencias, menos segregación? Argumentaremos en esa línea. La verdadera relación entre "lo social” y "lo espacial" -afirmaremos- no sería tanto una entre diferencias sociales y segregación espacial, sino que una más compleja entre procesos de diferenciación social y segregación residencial. Toda estructura social es dinámica y toda ciudad va transformando su estructura espacial. En efecto, el afán por construir o defender identidades sociales o de grupo representa uno de los factores que impulsan la segregación residencial, entendida ésta, por cierto, como un proceso permanente.

\section{Mito Tres. A las personas no les gusta vivir cerca de los de otra condición social}

Este es un argumento habitual entre gentes de derecha cuando buscan resistir las propuestas de reducción de la segregación residencial, especialmente la más radical de mezcla social en el espacio. El argumento consiste en una suerte de "clasismo" de derecha. Afirma, como un hecho auto-evidente que no requiere comprobación, que toda persona prefiere vivir con individuos parecidos. Los musulmanes con los musulmanes, los proletarios con los proletarios, los ABC1 con los $\mathrm{ABC} 1$, los negros con los negros².

1 De acuerdo a datos de los últimos dos censos de población en ambas ciudades. Los datos sobre la Capital Federal nos fueron facilitados por Mercedes di Virgilio de la Universidad de Buenos Aires.

2 ABC1: Estrato social cercano al 10\% de hogares de más altos ingresos en Chile. 
El argumento sigue con la declaración de que la segregación es, en buena medida, un hecho "natural", y que resulta ineficiente, además de ilusorio, resistirla. Es interesante advertir que esta hebra de raciocinio se combina muy bien con el tradicional "clasismo" de izquierda y con la "tesis del espejo". Las desigualdades, un hecho persistente en toda sociedad humana, se reflejarían en el espacio de las ciudades y, por lo mismo, la segregación sería natural. El argumento se aplica tanto a los grupos acomodados que no querrían vivir con otros de menor condición como a los de estratos más bajos que preferirían vivir con sus iguales.

Volveremos sobre este asunto con nuevos argumentos para refutar estas visiones. Baste por ahora dos botones de muestra. El primero es que, aun bajo la insondable discriminación racial que existe en los Estados Unidos, las encuestas muestran persistentemente que una clara mayoría de negros que viven en ghettos manifiestan preferencia por mudarse a barrios social y étnicamente más integrados (Squires et al., 2001). El riesgo de que esas personas sean objeto de formas directas de discriminación es alto y, sin embargo, igual preferirían mudarse a esos barrios.

El segundo botón de muestra fue la situación de laboratorio que representó el gobierno de la Unidad Popular en Chile (1970-73). El presidente Salvador Allende declaró que no reprimiría a las organizaciones populares, y en su gobierno se verificaron numerosas y masivas "tomas" de terrenos en el corazón del "barrio alto" de Santiago (el cono de alta renta donde se concentran los grupos medios-altos y de elite). La sagaz observación del arquitecto y urbanista Alfredo Rodríguez sobre la correlación existente entre precio del suelo y represión policial de las "tomas", encontraba respaldo. Si los invasores de tierras usualmente elegían lugares baratos para reducir el riesgo de la represión (el argumento de Rodríguez), ahora no debían hacerlo. Muchas "tomas" ocurrieron en el "barrio alto" durante el gobierno de Allende, "tomas" a cargo de organizaciones populares vinculadas a los partidos de izquierda. Las ideologías socialistas de transformación social, construidas en nociones fuertes de clase social, no parecen haber sido suficientes como para bloquear los afanes de integración social urbana de esos grupos populares.

\section{Claves de la integración social urbana}

Es habitual escuchar por estos días el argumento de que los chilenos somos demasiado "clasistas" como para aceptar mayores grados de integración socio-espacial. Para unos, el clasismo permite cerrar bien su cadena argumental determinista -globalización económica, (que causa) aumento de las desigualdades, (que dan forma a) mayor segregación residencial-. En último término, es un argumento fundado en el más paralizante de los pesimismos. Para otros, el clasismo parece excusarlos de colaborar en los intentos que pudieran hacerse desde la política pública para reducir la segregación. Se trataría de medidas forzosas, equivalentes a una suerte de ingeniería social discutible que, por lo demás, afectarían los negocios privados y el patrimonio de las familias.

Para ambas vertientes teórico-ideológicas la segregación aparece revestida de un hálito de necesidad o condición ineluctable. Esta noción "naturalista" de la segregación representa un poderoso freno para la construcción de los consensos políticos necesarios para inaugurar 
un campo nuevo de gestión pública, que creemos necesario en nuestro país, como es el del control de la segregación. Varias naciones desarrolladas de Occidente, lo mismo que países de otras regiones, están aplicando una serie de medidas en esta dirección, y América Latina aparece rezagada.

Para unos, la realidad del capitalismo de la "globalización" y su complemento de altos niveles de desigualdad social no pueden sino expresarse en una intensificación de la segregación residencial. La multiplicación de barrios cerrados de las clases medias y altas - gated comunities, en la terminología de los EEUU- es postulada como una demostración clara de que ese resultado se verifica. La combinación entre despliegue del capitalismo "global" y retrocesos significativos en la segregación, que es nuestra tesis sobre lo que está ocurriendo en Chile y otros países latinoamericanos, resulta un anatema. Por lo demás, tomar los muros de los nuevos condominios como indicadores de alzas en la segregación residencial, es al mismo tiempo una idea equívoca y un simplismo. De hecho, se podría argüir, con mejor base empírica y más consistencia lógica, exactamente lo contrario, a saber, que los muros han facilitado el emplazamiento de grupos medios y altos en zonas populares. Estarían facilitando disminuciones en la segregación.

Para otros, especialmente economistas de la tradición liberal, la segregación es un resultado "natural" de la operatoria de los mercados de suelo, articulados éstos por las preferencias y decisiones de localización de miles de agentes. Como veremos más adelante, el adjetivo de "natural" resulta discutible. La segregación puede resultar de forma espontánea (natural) de la concurrencia de numerosas decisiones de localización, pero por sobrepasar en promedio las preferencias de segregación de las personas que se localizan, es discutible que se la deba tratar como un hecho inevitable (natural).

La necesidad y las posibilidades que vemos de alcanzar mayores niveles de integración socioespacial en nuestras ciudades, las resumimos en las siguientes cinco claves: (i) La segregación espacial de los estratos populares es, hoy, un problema crítico de política pública, por lo que resulta urgente actuar en dirección de su control o atenuación; (ii) La proximidad física entre grupos sociales puede ser mayor cuanto más marcadas son las diferencias sociales, como ocurre en las ciudades de América Latina; (iii) Existen en nuestras pautas culturales urbanas significativos márgenes de libertad para la vecindad o proximidad espacial entre hogares de distinta condición social; (iv) Las motivaciones en que descansa la segregación espacial de los grupos sociales en nuestras ciudades dicen relación principalmente con la capitalización de "plusvalías" y menos con la defensa de identidades sociales vinculadas con las desigualdades y las diferencias sociales; y (v) El funcionamiento de los mercados de suelo produce niveles de segregación que exceden los que podrían justificarse por la preferencia de las personas.

Ninguno de estos argumentos tiene respaldo en estudios en el grado que sería deseable, dada la precariedad de la investigación científica sobre segregación residencial en el medio latinoamericano, incluido el chileno. Sin embargo, el conocimiento acumulado fuera de la región, especialmente en los Estados Unidos, lo mismo que los pocos estudios realizados en América Latina, les dan un sustento razonable. 
Primera clave. La segregación espacial de los estratos populares es un problema critico, por lo que resulta urgente actuar en dirección de su control

La segregación de los grupos populares en la periferia de las ciudades tiene impactos urbanos e impactos sociales. Entre los primeros destacan los problemas de accesibilidad y la carencia de servicios y equipamientos de cierta calidad en sus lugares de residencia; y entre los segundos, los problemas de desintegración social que están escalando hoy. Representan formas de empobrecimiento o de degradación social vinculadas a las desventajas que conlleva el aislamiento físico. Como observaron Blakely y Snyder en su influyente estudio sobre la proliferación de condominios cerrados en los Estados Unidos, "no hay contrato social sin contacto social" (1997).

Los primeros efectos, de tipo urbano, son conocidos. La segregación espacial hace que los grupos populares de nuestras ciudades sean aún más pobres. Pero los segundos efectos son relativamente nuevos, al menos la gran cobertura social que parecen estar cobrando.

En Chile, los estudios empíricos muestran que, en el pasado, antes de la década de los ochenta, la segregación espacial de los grupos populares no tenía los efectos de desintegración social que muestra actualmente. Incluso, algunas variables sociales como rendimiento escolar, empleo e inacción juvenil aparecían con mejores valores entre las zonas censales populares más segregadas (socialmente homogéneas) en comparación con zonas censales populares con mayor diversidad social (Sabatini, Cáceres y Cerda, 2001). La explicación es que esa segregación, en un contexto político de "centralidad de los marginales", según la célebre locución de Alain Touraine, favorecía la organización y el "empoderamiento" de esos grupos. Por cierto, el contexto que ofrecían las ciudades chilenas cuando se registraba ese impacto positivo podría constituir una excepción histórica, incluso a nivel internacional. Sin embargo, es una posibilidad, aunque ella haya perdido vigencia.

De tal forma, es posible concluir que, mientras en el pasado la segregación de las familias de menos ingresos tenía efectos tanto negativos como positivos, ahora se están agravando sus efectos más complicados de descomposición social. Iguales o, incluso, menores niveles de segregación espacial -en Santiago la segregación retrocedió en forma importante entre 1992 y 2002- estarían dando lugar hoy a fenómenos de "guetización" de los barrios populares (drogas, crimen, deserción escolar) que no existían antes o que eran mucho menores ${ }^{3}$. La "guetización" parece ser el último eslabón de un proceso que comienza con la reducción de las oportunidades. Un estudio reciente que compara similares conjuntos de vivienda "básica" en Santiago, Concepción y Talca -similares en población, diseño arquitectónico, antigüedad y nivel socioeconómico de los ocupantes originales-, muestra el peso de la segregación en las oportunidades de progreso. Entre los hogares que viven en los conjuntos más segregados es mayor el desempleo y menor la probabilidad de salir de la pobreza ${ }^{4}$. Un dato revelador de ese

3 Datos que avalan estas afirmaciones serán publicados en Sabatini, Wormald, Sierralta y Peters (2007).

4 Estudio de la Pontificia Universidad Católica de Chile, "Barrios en crisis y barrios exitosos producidos por la Política de Vivienda Social en Chile; 2005-7”, Programa Bicentenario en Ciencia y Tecnología del CONICYT, Chile. 
estudio indica que la mayoría de las mujeres que habitan esos barrios populares altamente segregados prefiere no trabajar (53,8\% inactivas) puesto que la compensación monetaria proveniente del ingreso mínimo al cual ellas generalmente pueden optar, no suple el gasto tanto en tiempo como en dinero que les implica trasladarse a los lugares de trabajo. A esto se suman la intranquilidad que les produce dejar sus casas e hijos solos durante todo el día, con el riesgo que puedan involucrarse en el consumo o tráfico de drogas, y el riesgo de caminar por lugares peligrosos.

Como señalamos antes, los grupos de menores ingresos de distintas ciudades y países, dada su mayor vulnerabilidad desde la reforma liberal de las economías, intentan defenderse de la segregación espacial. Mientras que hasta los años ochenta los problemas de exclusión que afectaban a los hogares de menores recursos equivalían a una "modernización trunca", ahora consisten en formas de "integración precaria" (Wormald, 2007). La pobreza ha disminuido, pero la probabilidad que los que la superan vuelvan a ella, es mayor ahora que décadas atrás. En términos de los efectos más propiamente sociológicos de la nueva situación, Rubén Kaztman (2007) argumenta sobre la transformación de "los barrios de la nueva pobreza urbana en focos territoriales de anomia, cuya presencia contribuye fuertemente a la erosión de la calidad de las relaciones sociales en las ciudades" (2008, p. 16).

Las "tomas" de terrenos en la comuna de Peñalolén en la ciudad de Santiago en años recientes ilustran bien la importancia que la segregación está cobrando para los grupos populares. Éstos luchan, ya no por el derecho a la "casa propia" como en décadas pasadas, sino que por habitar inmersas en las redes y oportunidades que entrega la ciudad. Su objetivo ha sido permanecer en su comuna y no ser trasladadas a viviendas sociales en la periferia alejada. Los procesos de gentrificación que ha sobrellevado este municipio popular han traído un alza generalizada de los precios del suelo y, con ello, la dificultad de poder construir nuevos conjuntos de vivienda social allí.

Desde una perspectiva territorial, estamos siendo testigos de una naciente "lucha por la ciudad”. En su declaración pública del 13 de marzo de 2006, al día siguiente del fallido intento de tomarse varios terrenos en el municipio, el Movimiento de Allegados en Lucha de Peñalolén denunciaba: "Mientras vemos cómo se construyen viviendas lujosas y grandes parques para los ricos de la comuna, nosotros nos vemos forzados a migrar hacia la periferia, a lugares donde hoy no hay empleo ni tampoco servicios básicos, como hospitales o colegios". La demanda principal de esos pobladores era, según el mismo comunicado, "una vivienda digna en Peñalolén"5.

Si bien el proceso vivido por las familias allegadas y de campamentos de la comuna Peñalolén ha sido muy conocido, no se trata de un fenómeno aislado. ${ }^{6}$ La demanda de los "pobladores" por estar mejor ubicados en la ciudad es generalizada. Se expresa, por una parte, en los patrones de localización de los "campamentos" (asentamientos informales) a lo largo del país; y,

\footnotetext{
$5 \quad$ www.latercera.cl, marzo 16 de 2006.

6 Campamento: asentamiento irregular originado de una invasión o "toma" de terrenos por parte de un grupo organizado de familias, generalmente con vinculaciones con partidos políticos.
} 
por otra, en estrategias a nivel de los hogares, como el de "allegarse" en casa de otras familias, arrendar piezas, o comprar una vivienda usada con el Subsidio Habitacional. En este último caso, las familias se inclinan por una vivienda de segunda mano en vez de una nueva, fundamentalmente porque pueden elegir su lugar de residencia.

Si se observan los puntos de emplazamiento de los 533 campamentos existentes en Chile (28.578 familias residentes) -datos del Catastro Nacional de Campamentos 2007 de la Fundación Un Techo Para Chile -, se advierte que aquéllos no se localizan en forma indistinta en cualquier región, zona o ciudad del país. Un 73 por ciento de los campamentos se encuentran al interior o cercanos a las ciudades más grandes y pobladas del país. De tal manera, las regiones y ciudades que concentran el mayor número de residentes de campamentos corresponden, justamente, a las tres áreas metropolitanas de Chile: Santiago (122 campamentos), Concepción (70 campamentos) y Valparaíso (55 campamentos).

Aun más, la mayoría de estos campamentos se encuentran localizados cerca de fuentes laborales, como plantaciones agrícolas, áreas forestales o espacios intersticiales de las áreas urbanas, estos últimos usualmente de alto riesgo, como es el caso de riberas de ríos, basurales, quebradas y orillas de carreteras. Estos espacios intersticiales son de los pocos deshabitados que van quedando al interior de las ciudades. El alto grado de formalización de la propiedad que existe en Chile, fundado en un derecho de propiedad estricto y bien protegido, elimina casi por completo la posibilidad de encontrar dentro de las ciudades espacios libres o "sin dueño". Así, las grandes ocupaciones ilegales de terreno de antaño ya no parecen posibles. Han sido sustituidas por pequeños grupos dispersos por la ciudad que muestran el ánimo de no ceder en la búsqueda de un emplazamiento que mejore su "geografía de oportunidad".

A lo anterior se suma el hecho de que una proporción apreciable de familias de campamentos que han sido erradicadas hacia conjuntos de vivienda social no están satisfechas. Declaran preferir su anterior vida en el campamento que la que les brinda su nueva casa; y dentro de los motivos que señalan, está un reducido nivel de complacencia con el barrio en el cual se insertaron, baja confianza en los vecinos y aumento de la sensación de inseguridad (Concha, del Campo y Brain, 2003). Estudios encargados por el Ministerio de Vivienda y Urbanismo apuntan en la misma dirección: un alto porcentaje de las familias, que a veces supera el $50 \%$, manifiestan preferencia por los campamentos antes que por sus nuevas casas (MINVU/INVI, 2002). Además, la intención de permanecer en las nuevas viviendas disminuye con el paso del tiempo (MINVU/INVI, 2002), en vez de aumentar como era tradicional en las ciudades chilenas.

En cuanto a las familias que viven como allegadas o que arriendan piezas, un estudio realizado en Santiago muestra que las familias prefieren utilizar el Subsidio Habitacional para la compra de vivienda social de segunda mano $^{7}$ porque tienen más posibilidades de elegir tanto la vivienda (la cual puede tener ampliaciones) como su localización (barrio y comuna) (Brain

\footnotetext{
El Subsidio Habitacional denominado Fondo Solidario de Vivienda, destinado a los hogares de menores ingresos, contempla la posibilidad de que el subsidio se destine a la compra de viviendas usadas, asignando un subsidio máximo de 280 UF, a lo cual se suman 10 UF de ahorro mínimo por parte de las familias que postulan a este subsidio. Ver: http://www.minvu.cl/default2 asp?cuerpo $=475$
} 
et al., 2005). Parecen dispuestas a sacrificar metros cuadrados de su vivienda e, incluso, cambiarse de una casa a un departamento, siempre y cuando este último esté ubicado más cerca del centro de la ciudad. Por cada kilómetro más cerca del centro de la ciudad, el estudio muestra que las familias están dispuestas a sacrificar 7,5 metros cuadrados de su vivienda.

Por otra parte, según los resultados de una encuesta sobre preferencias de regulación urbana realizada el año 2006 en las tres principales ciudades chilenas, la población prioriza una mejor localización de la vivienda social por sobre aumentos de su tamaño, como manera de mejorar las soluciones habitacionales (69\% de los encuestados) (ProUrbana y OSUAH, 2006). Junto con ello, el $70 \%$ apoya una ley que obligue a todas las comunas a acoger viviendas sociales con el fin de evitar la concentración de éstas en algunas zonas de las ciudades. Estos resultados no sólo son consistentes con la tendencia internacional que exhiben los grupos urbanos vulnerables en cuanto a mejorar su localización, como seńalamos para los casos de Rio de Janeiro, Buenos Aires y las áreas metropolitanas de los Estados Unidos, sino que, además, muestran que ese objetivo es apoyado por personas de todos los grupos sociales. Su preferencia porque se establezca una ley como esa, en vez de que las viviendas sociales se construyan donde los terrenos son más baratos, fue declarada por un 76,2\% de los entrevistados del estrato $\mathrm{E}$ y un $65,8 \%$ de los $\mathrm{ABC} 1$, marcando porcentajes intermedios los restantes grupos.

\section{Segunda clave. Las marcadas desigualdades sociales hacen posible alcanzar niveles significativos de proximidad fisica entre los grupos sociales urbanos}

Lo de "significativos" niveles de proximidad física que se podrían lograr en nuestro medio se refiere, por una parte, a que son mayores que lo que habitualmente pensamos; $y$, por otra parte, a que la segregación que exhiben nuestras ciudades chilenas y latinoamericanas es significativamente más reducida que la de las ciudades de otras regiones, especialmente los Estados Unidos.

El primer punto se relaciona con los enfoques que "naturalizan" la segregación. Como los chilenos somos "clasistas", nuestras ciudades las percibimos como altamente segregadas y sus residentes como refractarios a mayores grados de aproximación espacial entre grupos sociales. Sin embargo, la realidad parece desmentirnos.

Pensemos en la multiplicación de proyectos, por lo general del tipo "barrios cerrados", que se construyen hoy en la periferia popular, con buenos resultados comerciales. Por una parte, están los "pobladores" de estas comunas, que evalúan positivamente la llegada de los nuevos conjuntos "gentrificadores", tanto en términos simbólicos ("somos todos chilenos") como de ventajas laborales, urbanísticas y de servicios - estudios en "poblaciones" de Santiago que dan cuenta de esta conformidad, son los que se recogen en Cáceres y Sabatini (2004)-. Por otra parte, están las familias de estratos medios y altos que se mudan a comunas populares. En la misma línea, la encuesta del PNUD de 2002 contabilizó en 63,3\% la proporción de chilenos que dicen no tener problema en vivir cerca de familias más pobres que ellos (PNUD, 2002).

De hecho, está consolidándose una nueva tendencia en el desarrollo urbano contemporáneo, que es la colonización de áreas internas de bajos ingresos por proyectos inmobiliarios dirigidos a las clases medias y altas. El sector de promoción inmobiliaria, fortalecido por la liberalización de 
los mercados de suelo y, en general, por la reforma neoliberal de las economías, está mostrando capacidad de mutación de las ciudades. Los promotores compran suelo "a precio obrero" y lo revenden, con nuevas edificaciones sobre él, a compradores de ingresos altos, capitalizando ingentes rentas de la tierra. Destacan los procesos masivos de gentrificación que están transformando aceleradamente las áreas centrales de las ciudades de los Estados Unidos. Muchos complejos de vivienda pública están siendo demolidos, incluidos algunos de los más célebres guetos negros, sus residentes expulsados y el suelo entregado a promotores que construyen viviendas en condominios para grupos acomodados.

En nuestro medio latinoamericano la gentrificación afecta a la periferia popular, pero podría tratarse de una "gentrificación sin expulsión", esto es, de una invasión de los más ricos que no da lugar necesariamente a la expulsión de los residentes de menores ingresos (Sabatini, Vásquez, Robles y Rasse, 2008). Por tratarse de la periferia, los "gentrificadores" encuentran sitios eriazos; y por predominar entre los residentes de condición popular formas de tenencia del suelo distintas que el arrendamiento (ya sea la informalidad o la propiedad privada de la vivienda social), la expulsión es más difícil. El resultado espontáneo es la reducción de la distancia entre los grupos sociales que ocupan los extremos de la escala social, es decir, una reducción de la segregación residencial.

La gentrificación latinoamericana es, por otra parte, generalizada en la escala social (también los grupos medios invaden las áreas populares) y engloba más actividades que las residenciales. Los shoppings y los modernos complejos de oficinas tienen asimismo como alternativa de localización a la periferia popular, ahora accesible con la proliferación de obras públicas, especialmente carreteras.

El punto central es que, además de los factores urbanísticos que explican esta gentrificación sin expulsión, estarían influyendo factores culturales y económicos que discutiremos en las siguientes páginas, y que apuntan a mayores grados de mezcla social en el espacio.

En términos generales, los barrios y sectores internos de las ciudades latinoamericanas, especialmente las de menor tamaño, muestran un grado importante de diversidad social. Un dato clave a tener en cuenta, es que en esas ciudades de tamaño moderado los mercados de suelo no presentan el dinamismo y desarrollo que se da en las grandes ciudades. Argumentaremos más adelante, justamente, que los mercados de suelo parecen tener más responsabilidad en la segregación que las diferencias sociales e, incluso, que las preferencias residenciales "clasistas" de las personas.

El segundo punto es destacar que los niveles habituales de segregación social del espacio son bastante menores en las ciudades chilenas y latinoamericanas en comparación con las de los Estados Unidos. El contraste entre Brasil y Estados Unidos es decidor. Ambos países tienen en común su gran tamaño y una importante población negra originada en la esclavitud, pero difieren en que Brasil es uno de los más desiguales del planeta mientras que los Estados Unidos muestran una distribución del ingreso mucho más pareja. Sin embargo, la segregación es prácticamente el doble en las ciudades de los Estados Unidos comparada con la existente en 
las brasileñas (Telles, 1992) ${ }^{8}$. Las claves sociológicas y urbanas de la generación de tan altos niveles de segregación residencial en las ciudades de los Estados Unidos, han sido abordadas en numerosos estudios, aunque la discusión se mantiene viva y, por cierto, inconclusa (ver, entre otros, Wilson, 1987; Massey y Denton, 1993; Orfield, 1997; Jargowsky, 1997; Blakely y Znyder, 1997; y, entre los más recientes, Bennett et al., 2006).

En su estudio histórico del origen de la "ciudad del suburbio", o modelo anglo-americano de ciudad capitalista, Robert Fishman (1987) reconoce sorprenderse por el hecho de que las extremadamente desiguales ciudades pre-industriales "hayan tolerado" tan alto grado de proximidad y contacto físico entre ricos y pobres, mientras que las ciudades más igualitarias de los siglos XIX y XX hayan buscado evitar esos contactos. De hecho, la ciudad europea pre-industrial se caracterizó por una "combinación entre proximidad física y vastas distancias sociales”, en palabras de Watt (1963, p. 185). Y en la época contemporánea no sólo destaca la alta segregación residencial en las ciudades del igualitario Estados Unidos, sino también la realidad poco segregada de las ciudades de la India, el país que quizás tenga la estructura social más jerarquizada y rígida del planeta?. En suma, los casos concretos de ciudades, los que hemos mencionado y muchos otros, echan por tierra las nociones que buscan "naturalizar" la segregación en las desigualdades y el clasismo.

Woolf (1989), en su estudio histórico de los grupos pobres en Europa, destaca la "asistencia a domicilio", consistente en formas espontáneas de atención a la pobreza que surgían de la vida residencial en los espacios socialmente mezclados de la ciudad pre-industrial. Se trató de mecanismos que irían debilitándose con la afluencia masiva de inmigrantes pobres. La segregación espacial de los recién llegados hacia los extramuros los volvería invisibles, contribuyendo a que el Estado tuviera que crear instituciones especializadas para enfrentar la pobreza (Woolf, 1989).

Le Goff destaca el aporte del Cristianismo en consolidar, en las ciudades de la Europa tardomedieval, lo que denomina "apología de la pobreza", y que entiende como una ideología que conforta tanto a quienes triunfan (las ciudades se volvían prósperas) como a quienes seguían abrumados por las carencias materiales (1999, p. 73). Enarbolando la potente imagen del Cristo sufriente, los cristianos ayudaron a crear unos lugares, las ciudades de la Baja Edad Media, en que las personas cuidaban las unas de las otras, aun en medio del crecimiento económico y su requisito de mayores libertades e iniciativa individual (Sennett, 1997, p. 171). En esas ciudades, destaca George Duby, "no existía la espantosa soledad del miserable que vemos en nuestros días", y agrega, precisando: "existía el miedo a la súbita penuria, pero no la exclusión de una parte de la sociedad así ocluida en desesperanza” (1995, pp. 27-28).

\footnotetext{
$8 \quad$ Edgard Telles compara los índices de segregación residencial de la población negra, que es mayoritariamente pobre, en las 10 principales ciudades brasileñas y las 6 más grandes de los Estados Unidos. El índice de disimilaridad varía entre 0,76 (Chicago) y 0,87 (Detroit) en las segundas; mientras que varía entre 0,37 (Sao Paulo) y 0,48 (Salvador) en las ciudades brasileñas. La disimilaridad puede presentar valores en un rango de 0 a 1 y su valor, multiplicado por 100, indica el porcentaje de población del grupo estudiado que tendría que mudar su residencia a otra área para llegar a una situación de ausencia de segregación.
}

9 Ver en la Revista ProUrbana un interesante reportaje sobre la segregación residencial en la India y otros países (www.prourbana.cl). 
La observación de Watt sobre las ciudades europeas previas al capitalismo, podríamos refrasearla así: "eran tan vastas las distancias sociales que no había necesidad de segregarse en el espacio". En contraste, cuando las diferencias sociales son amenazadas o se vuelven borrosas, entonces los grupos sociales buscarán segregarse para defender sus identidades colectivas. Esto es, precisamente, lo que han exhibido las ciudades del país más rico y dinámico del mundo en los últimos cien años: los Estados Unidos. Cuando la movilidad social se hace masiva y se reducen las desigualdades, entonces la segregación espacial pasa a ser un recurso para afirmar identidades sociales que son débiles, ya sea porque están en creación (grupos medios emergentes) o porque son amenazadas por los cambios (minorías en riesgo de desaparecer como identidades reconocidas).

El efecto de este factor identitario en la evolución de la segregación residencial lo podríamos denominar "adolescencia urbana" ${ }^{10}$. De igual manera como los adolescentes recurren a identidades algo artificiales para mejorar su entrada al mundo adulto, los nuevos grupos medios recurren a la segregación espacial como manera de fortalecer su nueva identidad colectiva. Son especialmente celosos de impedir que lleguen a vivir a sus barrios aquellos con quienes pueden ser socialmente confundidos: las personas de las categorías sociales más bajas de donde ellos mismos provienen. Así, la segregación residencial opera como una suerte de "blindaje social" de estas personas y familias -el término es de Martim Smolka, economista brasileño y Director del Programa Latinoamericano del Lincoln Institute of Land Policy, quien nos lo sugirió en una conversación.

Sin embargo, las ciudades de Europa continental, donde el crecimiento económico y la movilidad social ascendente han sido también importantes, no han alcanzado nunca los niveles de segregación que las ciudades de los Estados Unidos; así tampoco sus niveles de violencia urbana. El antropólogo Marvin Harris postuló tempranamente una vinculación entre los altísimos niveles de violencia y crimen de las ciudades de los Estados Unidos, muy por encima de los de ciudades equivalentes en tamaño y nivel de desarrollo de otros países, y la discriminación racial y segregación residencial (Harris, 2000). ¿Por qué existen esas diferencias entre Europa y Estados Unidos? La diferente matriz cultural, en gran medida constituida en el período colonial, entrega una posible clave.

Tercera clave. El ethos cultural católico de nuestras ciudades ofrece importantes márgenes de libertad para la proximidad espacial, incluso la vecindad, entre personas de distinta condición social

Mientras que el proyecto colonizador ibérico en la América meridional se construyó con una combinación de motivaciones materiales e interés cristiano en la conversión de almas (Zea, 1978), el proyecto anglo y puritano en la América septentrional iría construyendo una noción sospechosa, indiferente y, al final, excluyente del "otro", especialmente en las tierras que hoy hacen la mayor parte de los Estados Unidos.

10 Sennett hizo la conexión entre la teoría sicológica de la adolescencia y los fenómenos urbanos para las ciudades de los Estados Unidos (1970), y nosotros la especificamos para el caso de las ciudades latinoamericanas (Sabatini, 2003). 
Zvetan Todorov recrea con sensibilidad y sutileza las diferentes formas de encuentro con el "otro" que cruzan la historia colonial de la América española (1991). Todas ellas tienen en común la realidad del reconocimiento en la igualdad esencial, alcanzando a veces el paroxismo de la admiración más desenfrenada por los indios o, al revés, modalidades de asimilación forzada que negaban la realidad cultural del "otro". El panorama no estuvo nunca libre de conflictos y de dudas, como los que cruzaron la historia del Padre Las Casas y, finalmente, el mismo "debate de Valladolid" cuando aquél, ya anciano, fue enjuiciado por haber llevado su defensa de los indios a una suerte de relativismo teológico que justificaba todos los caminos a Dios.

Las imágenes que se fueron construyendo de las tierras de ultramar no fueron nunca seguras ni libres de controversia. Las ideas de una felicidad natural e inocente como la del Edén se combinaban con las del salvajismo más desenfrenado, la tortura y el desuello (Calvino, 1998, p. 25). En una suerte de juego de espejos, Tomás Moro escribió su Utopía con base en los relatos idealizados que hicieron los primeros exploradores sobre los moradores del Nuevo Mundo, Utopía a la que luego recurrirían algunos conquistadores para diseñar modelos de sociedad a los que los indios serían forzados a asimilarse, como fue el proyecto de Vasco de Quiroga en México (Todorov, 1991, p. 205). A pesar de los titubeos y las discusiones, el sustrato era, sin embargo, claro: el reconocimiento del indio como hijo de Dios, más allá de sus sorprendentes y a veces espeluznantes costumbres.

Esta noción del "otro" fue "ilustrada", en el sentido no sólo de haber estado fundada en la idea de la igualdad de todos los hombres, sino también de que ella fomentaría ulteriores procesos de mestizaje en el nuevo continente, parecidos a los que construyeron las sociedades europeas que anidaron la Ilustración. La Conquista ibera asumió la superioridad de la cultura y la sociedad europea y buscó la asimilación del indio y el desmantelamiento de su cultura, siendo el "resultado racial" de este encuentro, el mestizaje (Zea, 1978, p. 104-5).

El proyecto anglo y puritano, en cambio, y a pesar de compartir el desprecio por la cultura del aborigen, no se planteó tarea alguna en relación con la conquista de almas o la asimilación, dice Leopoldo Zea (1978:134). En una primera etapa, fue un proyecto netamente comercial. Eran colonizadores y no conquistadores. Y, más tarde, la llegada de los puritanos que huían de las guerras religiosas, como los que llegaron en el Mayflower al puerto de Boston, no cambiaría mucho las cosas en lo que se refiere a la relación con el indio: lo seguirían ignorando (1978: 133-144).

La clave estaba en el principio teológico de la predestinación: se trataba de los elegidos por Dios para construir la Nueva Jerusalén, los que trabajarían duramente la tierra con el fin de producir los signos de su propia salvación. Los indios, en cambio, eran parte de esa gran mayoría de seres humanos que, según San Agustín, estaba destinada a irse al Infierno. "Los indígenas estaban, simplemente, sobrando", sentencia Zea (1978:136).

Premunidos de los ideales de libertad personal, de conciencia y de creencia, por los que habían luchado en sus tierras de origen, los puritanos ayudarían a crear esa peculiar combinación entre libertad y tolerancia, de una parte, y exclusión e indiferencia, por otra, textura que caracteriza hasta hoy a la sociedad estadounidense. Al analizar el clima social y sicológico que impera en 
la Nueva York actual, Richard Sennett enfatiza la mezcla de indiferencia y tolerancia que allí se constata (1997: 378-382).

Tal "indiferencia tolerante" parece estar en el núcleo de la cultura urbana de ese país, lo que resulta coherente con su matriz religiosa. La noción calvinista de la predestinación, más allá de que actualmente las denominaciones religiosas principales y la enorme profusión de nuevas sectas reconozcan o no formalmente ese principio teológico, ha quedado reverberando en los patrones culturales de dicha nación (ver Phillips, 2006). De la misma forma, el "capitalismo victorioso" posterior al siglo XVIII ya no requirió del "apoyo religioso" que le brindara en sus inicios la "ética protestante", y específicamente el "ascetismo intramundano" calvinista basado en la idea de la predestinación (Weber, 2003:286). Las ideas religiosas son incorporadas a los patrones culturales y siguen influyendo en la vida social "como un fantasma de ideas religiosas ya pasadas", como señala Max Weber (2003:286).

Kevin Phillips, antiguo estratega republicano y asesor del presidente Richard Nixon, en su reciente libro sobre los Estados Unidos argumenta, con base en numerosos estudios, sobre la fuerza que tienen hoy nociones religiosas, rayanas en el fundamentalismo, que son consistentes con la idea de la predestinación (2006). Dos rasgos que destaca del Cristianismo en ese país, y que se han fortalecido en los últimos decenios son, por una parte, "la búsqueda individual de la salvación a través del renacimiento espiritual", y por otra, el hecho de que "ninguna otra nación occidental contemporánea comparte esta intensidad religiosa y su consiguiente proclamación de que los estadounidenses son el pueblo y la nación elegidos de Dios" (Phillips, 2006:100-1 -traducción nuestra).

Tal vez sin quererlo, Beatriz Sarlo resume elocuentemente la diferencia entre estas culturas urbanas cuando señala que en la América Latina no existen "identidades con guión” como las que observamos en los Estados Unidos. Llamar afro-americanos a ciudadanos cuyos abuelos ya habían nacido en los Estados Unidos, es una sutil forma de discriminación, por más que existan programas y leyes de apoyo a esas "minorías". En Brasil no se habla de afro-brasileños como tampoco en Argentina se habla de ítalo-argentinos; se los llama, simplemente, brasileños y argentinos. "No hay identidades con guión, no hay fractura cultural", afirma Sarlo (2007). La aceptación del "otro", la posibilidad del encuentro y el mestizaje, parecen más plenos y llanos en nuestra matriz cultural urbana, de raíz católica, en comparación con la de los Estados Unidos.

En "La Política", Aristóteles afirmaba que una ciudad está compuesta de diferentes clases de hombres, y que gente similar no puede dar origen a una ciudad. Tal vez no haya mejor definición de ciudad que esa; y mejor posibilidad de realizar esa integración en diversidad que la que provee el marco histórico del Catolicismo, separado de la noción de predestinación, como lo muestran la cultura urbana de la Europa continental y la de la América Latina.

En suma, el encuentro con el "otro", que está en la esencia misma del hecho urbano, ha tenido muy diferentes formas de realizarse en las ciudades de Occidente según las distintas tradiciones cristianas. La ciudad anglo-americana, de base protestante, se fundó en una noción sospechosa del "otro", tributaria de la tesis de la predestinación de San Agustín, tesis que 
rescatara y potenciara el calvinismo y que discrimina entre una minoría de elegidos y una mayoría de condenados al infierno. Por contraste, la ciudad católica se construyó en la idea de que todos, españoles e indios, ricos y pobres, son hijos de Dios con iguales posibilidades de llegar al Reino de los Cielos.

La primera ciudad, asentada en un marcado anti-urbanismo, está cruzada por una mezcla entre tolerancia y profunda indiferencia hacia el "otro"; y la segunda, que se asume a sí misma como una comunidad, ha sido dominada por los afanes de asimilación que han violentado o derechamente avasallado las culturas aborígenes o populares. En todo caso, la indiferencia radical de la primera ha demostrado ser socialmente más devastadora que el "asimilacionismo" que ha practicado la segunda. En los últimos cien años, las ciudades de los Estados Unidos han sido más segregadas y con niveles de criminalidad y violencia más altas que las latinoamericanas y las europeas.

\section{Cuarta clave. La segregación en nuestras ciudades es más el resultado de la búsqueda de "plusvalías" que del afán por consolidar diferencias entre grupos sociales.}

La valorización de la propiedad inmueble, sea como negocio de loteadores o de promotores, o como patrimonio familiar, es un factor contribuyente a la homogeneidad social del espacio que, muy probablemente -en la línea del razonamiento de Thomas Schelling que examinaremos luego - exceda las preferencias de segregación de los grupos altos y medios. Desigualdades y jerarquías sociales claras, como las que han prevalecido en nuestro medio, no requieren de altos niveles de segregación, por lo que la explicación principal de la segregación habría que buscarla en otros factores, entre los que se cuentan los económicos vinculados a los mercados de suelo.

Muchas familias acomodadas prefieren evitar la cercanía de gente más pobre porque, de acuerdo a una creencia común, ello podría obstaculizar la valorización de sus propiedades. Así, esta idea opera como una profecía auto-cumplida. Es, no obstante, una creencia sin fundamento empírico. Estudios recientes que han evaluado el impacto de programas de dispersión espacial de vivienda económica en ciudades de los Estados Unidos, donde hay más celo segregador que en América Latina por las razones antes señaladas, han descartado esos efectos en los mercados de inmuebles. Es de destacar el estudio econométrico hecho por investigadores del Massachusetts Institute of Technology sobre el impacto de siete complejos de vivienda económica dispersos en suburbios del Área Metropolitana de Boston que parecían especialmente agresivos con sus vecindarios (Pollakowski, Ritchay y Weinrobe, 2005). Con largas series de precios de la vivienda compararon el área de impacto de esos proyectos con un área de control mayor, constatando la ausencia de dichos impactos negativos ${ }^{11}$.

La ruptura del confinamiento de los grupos altos y medios-altos en los "barrios altos" de nuestras ciudades a través de la construcción de condominios cerrados en otras áreas de las ciudades, incluida su periferia popular, respalda nuestra afirmación. Cuando existe pie para la capitalización

11 Parecido resultado arrojó el estudio de Briggs, Darden y Aidala (1999) para el caso del programa de reducción de la segregación residencial aplicado en Yonkers, Nueva York, en los años 1990. 
de rentas del suelo a través de los proyectos inmobiliarios, tanto a favor de promotores como de compradores, la segregación puede reducirse. En un estudio sobre la formación histórica de los "barrios altos" de Valparaíso, Santiago y Concepción se encontró que aun los barrios que nacen como más elegantes pronto registran subdivisiones de sus lotes originales para ser vendidos a familias más modestas e, incluso, para la construcción de conventillos destinados al arrendamiento a familias pobres ${ }^{12}$. Ese tipo de intervenciones, por contraste, son explícita y decididamente resistidas en los suburbios de las ciudades de los Estados Unidos.

El suburbio en el medio latinoamericano es más una realidad física, que toma elementos arquitectónicos y urbanísticos de la tradición anglo-americana, que la organización de vecinos para la exclusión social y la construcción de identidades de grupo, que es en lo que consiste básicamente el suburbio en los Estados Unidos. Aunque los elementos de valorización inmobiliaria y de construcción de identidades de grupo están presentes en ambas realidades, tienen un peso distinto, lo que tiene implicancias de fondo para el diseño de políticas. La secular inestabilidad de las economías latinoamericanas, por una parte, y el carácter más compartimentado de la estructura social, por otra, otorgarían más influencia en la segregación a la valorización inmobiliaria que a la formación de identidades de grupo social.

Otras motivaciones de la segregación son las relativas a la calidad de vida. Los grupos que tienen posibilidad de elegir su localización en la ciudad buscan el acceso a bienes públicos o colectivos (bienes a los que difícilmente se accede en forma individual) agrupándose en el espacio. La segregación permite, así, mejorar las posibilidades de las familias de acceder al paisaje, la naturaleza, el medio ambiente y la seguridad ciudadana. En medida importante, la conformación de una suerte de cono geográfico de concentración de los grupos altos y medios en la ciudad latinoamericana del siglo XX se puede explicar por estas externalidades de vecindad. A su vez, la consolidación de un área con tales ventajas refuerza el mecanismo de segregación que está anclado en el funcionamiento de los mercados de suelo. La formación de precios "de expectativa", que son especialmente altos en esas zonas favorecidas, contribuye a revertir la relación causal entre usos y precios del suelo, consolidando un mecanismo automático de exclusión de quienes no pueden pagar tanto por el suelo.

La liberalización de los mercados de suelo, la concentración del capital inmobiliario, la adopción de la tipología del condominio cerrado o enrejado, y la realización de importantes obras de infraestructura urbana de nivel regional, especialmente en vialidad y transporte, se cuentan entre los factores que están contribuyendo a modificar el patrón tradicional de segregación desde los ańos ochenta, aproximadamente. Por el mayor tamaño de sus proyectos y un contexto material e institucional más favorable, los promotores inmobiliarios han comenzado a dispersar sus inversiones de superficies comerciales y residenciales fuera de las áreas donde el patrón tradicional de segregación hacía aconsejable localizarlas.

En particular, la localización de conjuntos residenciales para ingresos medios y altos en zonas de menor categoría social les permite capitalizar importantes rentas de la tierra. El tamaño

12 Proyecto FONDECYT 2002-4 "Valparaíso, Santiago y Concepción: formación de sus "barrios altos" (18921964). Publicaciones originadas de ese trabajo son Cáceres y Sabatini (2003 y 2007). 
relativamente grande de los proyectos les permite recrear la segregación residencial en una escala espacial más reducida. En efecto, como tendencia estos proyectos están favoreciendo un cambio de escala de la segregación. Ésta se hace más intensa en un nivel geográfico menor. La homogeneidad social de los nuevos conjuntos es alta, pero menor la distancia física a las zonas de residencia de grupos más pobres. Este es el resultado espacial de la gentrificación sin expulsión de que hablábamos antes.

En términos más generales, la reforma económica de los ochenta en América Latina (en Chile desde los setenta) abrió un período de transformación y crecimiento del sector inmobiliario privado y de radical transformación del patrón de segregación residencial que, paradójicamente, ha conllevado una reducción en la distancia física entre grupos sociales -esta tesis la desarrollan Sabatini y Cáceres (2004) y recibe respaldo empírico en un estudio para el caso de la ciudad de Santiago (Sabatini, Wormald, Sierralta y Peters, 2007).

\section{Quinta clave. Los mercados urbanos producen niveles de segregación residencial más altos que los} que resultarian de las preferencias de las personas

Este argumento tiene dos partes: La segregación puede ser mayor que las preferencias de localización segregada de quienes tienen capacidad de pago para elegir donde vivir; y la segregación puede ser excesiva en relación con las preferencias de segregación de los hogares de bajos ingresos con nula o muy baja capacidad de elegir su emplazamiento en la ciudad.

El primer argumento lo desarrolló tempranamente Thomas Schelling, Premio Nobel de Economía 2005, en su libro Micromotives \& Microbehavior (Norton, 1978) -una obra con importancia, más allá de la economía, para el conjunto de las ciencias sociales e, incluso, considerada uno de los pilares de las teorías de la complejidad-. Schelling demuestra cómo la confluencia de miles y miles de decisiones de localización produce ciudades más segregadas que las preferencias promedio de esos decidores ${ }^{13}$. $\mathrm{Si}$, por ejemplo, las personas prefirieran que al menos la mitad de sus vecinos fueran de su misma condición social, el "sistema emergente" de la ciudad podría producir, en cambio, un patrón de segregación en que las personas, en promedio, vivan con un $80 \%$ de vecinos similares.

Esta conclusión del modelo de Schelling sobre la segregación se complementa con otra, de relevancia para la política pública. Como hay una cuota de segregación que es excesiva en relación con las preferencias de las personas, existe un margen de acción para reducir la segregación sin afectar dichas preferencias: "para aquellos que deploran la segregación y especialmente para aquellos que deploran más segregación que el nivel que estaban buscando los que se auto-segregaron colectivamente, puede haber una nota de esperanza. La motivación subyacente puede ser mucho menos extrema que los patrones observables de separación" (Schelling, 1978, p. 154).

Es posible que el nulo efecto negativo sobre los precios de los inmuebles cercanos de los siete complejos de vivienda económica estudiados por el MIT, se deba precisamente a la existencia

13 Hay software disponible en Internet que simula modelos como los planteados por Schelling. 
de este margen. Tenemos, aquí, lo que en metodología de investigación se llama un caso crucial. Las grandes ciudades de los Estados Unidos, tal vez con la excepción de la católica Chicago, presentan con claridad los principales factores que producen segregación residencial: por una parte, "adolescencia urbana", dados los procesos de movilidad social productores incesantes de grupos medios urgidos de construir identidades sociales; y, por otra, una profunda distancia y desconfianza en el "otro" propia de su peculiar ethos cristiano. Sin embargo, complejos de vivienda económica "agresivos", como los de Boston, no generan efectos apreciables sobre los mercados locales de bienes raíces. Toda una paradoja que podría explicarse con la brecha entre preferencias de segregación y segregación "emergente” que identifica Schelling.

Un reciente estudio de Bishop (2008) registra para las ciudades de los Estados Unidos una forma peculiar de segregación "emergente" con origen en las mismas fuerzas "caóticas" que aludimos antes. En el mapa electoral de ese país ha ido aumentado el número de los condados landslide, definidos como aquellos en que el voto demócrata o el republicano aventaja al otro en veinte o más puntos porcentuales. Cuando Jimmy Carter ganó la presidencia en 1976, el 26,8 por ciento de los votantes vivían en condados landslide, y cuando George W. Bush ganó la reelección en 2004, esa proporción había subido a 48,3. El autor del estudio, William Bishop (2008), sostiene que las preferencias de lugar de residencia, ejercidas por numerosas personas que se inclinan por barrios con gente de gustos y estilos de vida afines, están llevando a una marcada segregación residencial entre republicanos y demócratas. La revista The Economist (junio 21, 2008) sintetiza la conclusión de ese estudio en un lenguaje que tiene resonancias de los análisis de Schelling: "porque los estadounidenses son tan móviles, incluso una leve preferencia por vivir con vecinos afines conduce a lo largo del tiempo a una severa segregación”.

Pero hay más en lo de Schelling. La interacción de estas miles de decisiones de localización, a partir de cierto momento, tiende a producir un equilibrio, o patrón de segregación espacial. El tratarse de una situación de equilibrio, no implica, sin embargo, que sea deseable. El mismo Schelling es enfático a este respecto: "una fuente innecesaria de desconfianza en el análisis económico es el supuesto de que cuando un economista discute el equilibrio está manifestando aprobación. Creo que ese supuesto es por lo general -no siempre, pero sí usualmente- un error" (Schelling, 1978, p. 27). En suma, por el hecho de que la segregación sea, hasta cierto grado, "natural" (espontánea), eso no quiere decir que sea buena ni que deba aceptársela.

Sin embargo, los modelos que trabaja Schelling están formados por personas que se pueden segregar; en terminología económica, por personas con capacidad de pago. ¿Qué hay de quienes, por pobreza, no pueden ejercer sus preferencias en los mercados? Lo que sucede es que son relegados a las opciones peores, tanto en lo material y urbano, como peores por ser distintas que lo que habrían elegido: ocupación ilegal de tierras, vivienda social y mercados informales de la vivienda.

La segunda parte de nuestro argumento es, justamente, que la segregación resulta excesiva en relación con las preferencias de localización de los hogares de bajos ingresos. Pero, ¿‘sabemos cuáles son esas preferencias? El enfoque "clasista” nos diría que lo esperable es que las personas prefieran vivir con sus iguales. Parece una inclinación clara la de las personas por integrarse en comunidades, en el sentido más lato del término, ya sean comunidades territoriales o no, o la 
de participar en la construcción de identidades colectivas. Sin embargo, las ciudades muestran que los grupos vulnerables o discriminados, especialmente cuando se precariza el empleo y se debilitan sus lazos con el sistema político formal, como ocurre hoy, prefieren vivir en barrios más integrados socialmente.

Hemos seńalado varios ejemplos de cómo esta es una tendencia en ascenso, tanto en otros países como en el nuestro. Las "tomas" de terrenos de décadas atrás en Santiago nos ofrecen, además, un claro indicio de que se trataría de una estrategia espacial persistente entre las clases urbanas populares. Como vimos antes, la alta concentración en el llamado "barrio alto" de esa ciudad de las "tomas" políticamente organizadas durante el gobierno de la Unidad Popular (1970-73), cuando el riesgo de la represión policial era prácticamente nulo, mostró, como en una suerte de experimento de laboratorio, cuáles eran las preferencias de localización de esos grupos populares. A pesar de estar imbuidos muchos de ellos de un militante clasismo de izquierda, buscaron el área socialmente más diversa y mejor equipada de la ciudad. Mal que mal, es posible argumentar que el objetivo más masivo de esas movilizaciones era la integración social, siendo los propósitos de transformación política más bien de los grupos dirigentes (Sabatini y Wormald, 2004).

\section{Conclusión}

Hemos ofrecido una serie de argumentos de por qué en el medio urbano latinoamericano habría posibilidades de reducción de la segregación residencial y de integración social urbana mayores que las que habitualmente anticipamos.

En lo sociológico, afirmamos que en sociedades tan desiguales y estratificadas como las de América Latina, los grupos sociales rara vez recurren al "comodín" de segregarse en barrios socialmente homogéneos para construir o afirmar identidades sociales. La "adolescencia urbana" suele ser un fenómeno ocasional y transitorio que irrumpe en algunas fronteras entre grupos sociales, a diferencia de la importancia y persistencia que exhibe en los Estados Unidos.

En lo cultural, sostuvimos que nuestra matriz cultural católica, a diferencia de la matriz puritana de los Estados Unidos, favoreció nociones más igualitarias - "ilustradas", afirmamos antessobre el "otro", esto es, sobre los diferentes a mí y los desconocidos que hacen la ciudad.

Finalmente, en lo económico argumentamos, de la mano de Schelling, que la segregación resultante en una ciudad suele exceder las preferencias de los que se auto-segregan, y agregamos que también excede las de quienes no tienen capacidad de pago para acceder a los expansivos mercados actuales de suelo y vivienda.

Nuestra convicción es que en el funcionamiento de los mercados de suelo está la clave de la segregación residencial en las ciudades chilenas y latinoamericanas, y que la relación entre segregación y rentas de la tierra es compleja, ofreciendo grados apreciables de libertad para políticas de control de la segregación. 
Los mitos y claves de la segregación que hemos analizado convergen en una conclusión principal: es enteramente posible y manifiestamente imperativo promover desde la política pública la evolución de nuestras ciudades hacia mayores niveles de integración socio-espacial, especialmente en favor de los grupos populares, tradicionalmente más segregados. La precarización del empleo y la marginación política que afecta a estos grupos urbanos, lo mismo en Chile como en muchos otros países, están convirtiendo los barrios en que ellos se aglomeran en guetos urbanos de desesperanza, violencia y crimen.

En particular, Chile se encuentra en inmejorables condiciones para enfrentar con buenas posibilidades de éxito esta lacra contemporánea. La reducción de la pobreza, el éxito cuantitativo de la política de vivienda social, la robustez de la economía y la estabilidad política, así lo indican. Sin embargo, hay que derrotar los mitos que paralizan nuestra voluntad y aprovechar las posibilidades que el sustrato social y cultural de nuestras ciudades ofrece para dichos propósitos.

\section{Referencias bibliográficas}

Bennett, Ll.; Smith, J. \& Wright, P. (Eds.) (2006). Where are poor people to live? EEUU: M.E Sharpe.

Bishop, B. (2008). The big sort: why the clustering of like-minded America is tearing us apart. Boston: Houghton Mifflin Co.

Blakely, E. \& Snyder, M. (1997). Fortress America. gated communities in the United States. Washington, DC: Brookings Institution Press-Lincoln Institute of Land Policy.

Brain, I.; Sabatini, F. \& Iacobelli, A. (2005). Evolución del valor de la vivienda social. Estudio del Programa de Apoyo a las Políticas Urbanas y de Suelo, ProUrbana UC -Lincoln Institute. Revista ProUrbana. Recuperado de www.prourbana.cl.

Briggs, X.; Darden, J. \& Aidala, A. (1999). In the wake of desegregation: early impacts of scattered-site housing on neighborhoods in yonkers, New York. Journal of the American Planning Association, 65, 1.

Cáceres, G. \& Sabatini, F. (2003). Para entender la urbanización del litoral: el balneario en la conformación del Gran Valparaíso (siglos XIX y XX). ARQ, 55.

Cáceres, G. \& Sabatini, F. (2007). Suburbanización y segregación urbana en el Chile decimonónico: hipótesis sobre la formación histórica del Gran Valparaíso. En J. Valenzuela (Ed.), Historias urbanas: homenaje a Armando de Ramón. Santiago: Ediciones Universidad Católica de Chile.

Calvino, I. (1998). Qué nuevo era el Nuevo Mundo. En I. Calvino, Colección de Arena. Madrid: Siruela.

Concha, M.; Del Campo, P. \& Brain, I. (2003). Estudio descriptivo de la situación posterradicación de las familias de campamentos en la Región Metropolitana. Revista CIS, 2. Santiago: Un Techo para Chile.

Duby, G. (1995). Año 1000, año 2000: la huella de nuestros miedos. Santiago: Editorial Andrés Bello.

Fishman, R. (1987). Bourgeois utopias: the rise and fall of suburbia. New York: Basic Books. Galster, G. \& Killen, S. (1995). The geography of opportunity: A reconnaissance and conceptual framework. Housing Policy Debate, 6, 1, 7-43. 
Harris, M. (2000). La cultura norteamericana contemporánea. Madrid: Alianza Editorial.

Jargowsky, P. (1997). Poverty and place: ghettos, barrios and the American City. New York: Russell Sage Foundation.

Jargowsky, P. (2003). Stunning progress, hidden problems: the dramatic decline of concentrated poverty in the 1990s. Presentación Power Point, University of Texas at Dallas.

Kaztman, R. (2007). La calidad de las relaciones sociales en las grandes ciudades de América Latina: viejos y nuevos determinantes. Revista Pensamiento Iberoamericano, segunda época, 1.

Le Goff, J. (1999). La civilización del Occidente Medieval. España: Paidós.

Massey, D. \& Denton, N. (1993). American apartheid: segregation and the making of the underclass. Cambridge, Mass: Harvard University Press.

Ministerio de la Vivienda y Urbanismo (MINVU) \& Instituto de la Vivienda de la Universidad de Chile (INVI) (2002). Sistema de medición de beneficiarios de vivienda básica: sintesis del informe de consultoría. Santiago: INVI y División Técnica de Estudio y Fomento Habitacional, MINVU.

Orfield, M. (1997). Metropolitics: a regional agenda for community and stability. EEUU: Brookings Institution Press \& Lincoln Institute of Land Policy.

Phillips, K. (2006). American theocracy. EEUU: Viking.

Pollakowski, H.; Ritchay, D. \& Weinrobe, Z. (2005). Effects of mixed-income housing, multifamily rental housing developments on single-family housing values. Cambridge: MIT.

Programa de Fomento de las Políticas Urbanas y de Suelo, Universidad Católica de Chile (ProUrbana) \& Observatorio Social de la Universidad Alberto Hurtado (OSUAH) (2006). Preferencias de regulación urbana en Chile. Encuesta a residentes de las áreas metropolitanas de Santiago, Valparaíso y Concepción. Recuperado de http://www.prourbana.cl.

Programa de las Naciones Unidas para el Desarrollo (PNUD) (2002). Informe de desarrollo humano en Chile 2002. Nosotros los chilenos: un desafio cultural. Santiago: PNUD.

Sabatini, F. \& Cáceres, G. (2004). Los barrios cerrados y la ruptura del patrón tradicional de segregación en las ciudades latinoamericanas: el caso de Santiago de Chile. En G. Cáceres \& F. Sabatini (Eds.), Los barrios cerrados en Santiago de Chile: entre la exclusión y la integración social. Santiago: Instituto de Geografía, PUC Chile.

Sabatini, F. \& Wormald, G. (2004). La guerra de la basura de Santiago: desde el derecho a la vivienda al derecho a la ciudad. EURE, 30, 91.

Sabatini, F. (2003). La segregación social del espacio urbano en las ciudades de América Latina. Documentos del Instituto de Estudios Urbanos, Serie Azul, 35. Santiago: Pontificia Universidad Católica de Chile.

Sabatini, F.; Cáceres, G. \& Cerda, J. (2001). Segregación residencial en las principales ciudades chilenas: tendencias de las tres últimas décadas y posibles cursos de acción. EURE 27,82 .

Sabatini, F.; Campos, D.; Cáceres, G. \& Blonda, L. (2006). Nuevas formas de pobreza y movilización popular en Santiago de Chile. En G. Saraví (Ed.), De la pobreza a la exclusión: continuidades y rupturas de la cuestión social en América Latina. Buenos Aires: CIESAS/ Prometeo.

Sabatini, F.; Vásquez, H.; Robles, S. \& Rasse, A. (2008). Gentrificación sin expulsión, fuerza de transformación de las ciudades latinoamericanas: datos e interpretación para Santiago. 
En F. Sabatini et al. (Eds.), ¿Cuán segregadas son las ciudades chilenas? Entre la integración y la exclusión social. Santiago: INE-UC (en prensa).

Sabatini, F.; Wormald, G.; Sierralta, C. \& Peters, P. (2007). Santiago 1992-2002: la segregación socio-espacial disminuye pero aumenta su malignidad. Documento de Trabajo, Instituto de Estudios Urbanos y Territoriales. Santiago: Pontificia Universidad Católica de Chile.

Sarlo, B. (2007). Identidad. Entrevista a Beatriz Sarlo, Perfiles de Intelectuales Latinoamericanos, Universidad Libre de Berlín. Recuperado de http://prof08b.lai.fu-berlin.de.

Schelling, T. (1978). Micromotives \& microbehavior. New York y London: Norton.

Sennett, R. (1970). The uses of disorder: personal identity and city life. New York y London: Norton.

Sennett, R. (1997). Carne y piedra: el cuerpo y la ciudad en la civilización occidental. España: Alianza Editorial.

Squires, G.; Friedman, S. \& Saidat, C. (2001). Housing segregation in the United States: does race matter? Ponencia presentada en el seminario internacional "Segregation in the city", Lincoln Institute of Land Policy, Cambridge, Mass., EEUU.

Telles, E. (1992). Residential segregation by skin color in Brazil. American Sociological Review, $57,2$.

Todorov, Z. (1991). La conquista de América: el problema del otro. México: Siglo XXI.

Watt, I. (1963). The rise of the novel: studies in Defoe, Richardson and Fielding. Harmonsworth: Penguin.

Weber, M. (2003). La ética protestante y el espíritu del capitalismo. México: Fondo de Cultura Económica.

Wilson, W. J. (1987). The truly disadvantaged. EEUU: The University of Chicago Press.

Woolf, S. (1989). Los pobres en la Europa moderna. Barcelona: Editorial Crítica.

Wormald, G. (2007). Presentación ante el Consejo Directivo de ProUrbana. Ciclo de reuniones sobre "Políticas de suelo para la integración social". Recuperado de http://prourbana. cl.

Zea, L. (1978). Filosofía de la historia americana. México: Fondo de Cultura Económica. 